\title{
1 Disentangling interactions among mercury, immunity, and infection in a Neotropical bat
} community

4 Daniel J. Becker ${ }^{1 *}$, Kelly A. Speer ${ }^{2-4}$, Jennifer M. Korstian ${ }^{5}$, Dmitriy V. Volokhov ${ }^{6}$, Hannah F.

5 Droke $^{7}$, Alexis M. Brown ${ }^{8}$, Catherene L. Baijnauth $^{9}$, Ticha Padgett-Stewart ${ }^{10}$, Hugh G.

6 Broders $^{11}$, Raina K. Plowright ${ }^{10}$, Thomas R. Rainwater ${ }^{12-14}$, M. Brock Fenton ${ }^{15}$, Nancy B.

7 Simmons $^{16}$, Matthew M. Chumchal ${ }^{17}$

8

$9 \quad{ }^{1}$ Department of Biology, University of Oklahoma, Norman, OK, USA

$10 \quad{ }^{2}$ Richard Gilder Graduate School, American Museum of Natural History, New York, NY, USA

$11{ }^{3}$ Department of Invertebrate Zoology, National Museum of Natural History, Smithsonian

12 Institution, Washington, D.C., USA

$13{ }^{4}$ Center for Conservation Genomics, Smithsonian Conservation Biology Institute, National

14 Zoological Park, Washington, D.C., USA

$15{ }^{5}$ Department of Biological Sciences, Texas Tech University, Lubbock, TX, USA

${ }^{6}$ Center for Biologics Evaluation and Research, Food and Drug Administration, Silver Spring,

17 MD, USA

$18{ }^{7}$ Department of Global and Planetary Health, University of South Florida, Tampa, FL, USA

$19{ }^{8}$ Department of Ecology and Evolution, Stony Brook University, Stony Brook, NY, USA

$20{ }^{9}$ Sackler Institute of Comparative Genomics, American Museum of Natural History, New York, $21 \quad$ NY, USA

$22{ }^{10}$ Department of Microbiology and Immunology, Montana State University, Bozeman, MT, USA

$23{ }^{11}$ Department of Biology, University of Waterloo, Waterloo, ON, Canada

$24{ }^{12}$ Department of Forestry and Environmental Conservation, Clemson University, Clemson, SC, 25 USA

$26{ }^{13}$ Baruch Institute of Coastal Ecology and Forest Science, Clemson University, Georgetown, SC, 27 USA

$28 \quad{ }^{14}$ Tom Yawkey Wildlife Center, Georgetown, SC, USA

$29{ }^{15}$ Department of Biology, Western University, London, Ontario, Canada

$30 \quad{ }^{16}$ Department of Mammalogy, Division of Vertebrate Zoology, American Museum of Natural

31 History, New York, NY, USA 
$32 \quad{ }^{17}$ Department of Biology, Texas Christian University, Fort Worth, TX, USA

33 *Corresponding author, danbeck@,ou.edu

34 Keywords: ecoimmunology; disease ecology; ecotoxicology; heavy metals; bacterial pathogens;

35 Chiroptera, Latin America

36 Running head: Mercury, immunity, and infection in bats 


\section{Abstract (350/350 words)}

1. Contaminants such as mercury are pervasive and can have immunosuppressive effects on wildlife. Impaired immunity could be important for forecasting pathogen spillover risks, as many land-use changes that generate mercury contamination also bring wildlife into close contact with humans and domestic animals. However, the interactions among contaminants, immunity, and infection are difficult to study in natural systems, and empirical tests of possible directional relationships remain rare.

2. We capitalized on extreme mercury variation in a diverse bat community in Belize to test association among contaminants, immunity, and infection. By comparing a previous dataset of bats sampled in 2014 with new data from 2017, representing a period of rapid agricultural land conversion, we first confirmed bat species more reliant on aquatic prey had higher fur mercury. Bats in the agricultural habitat also had higher mercury in recent years. We then tested covariation between mercury and cellular immunity and determined if such relationships mediated associations between mercury and common bacterial pathogens . As bat ecology can dictate exposure to mercury and pathogens, we also assessed species-specific patterns in mercury-infection relationships.

3. Across the bat community, individuals with higher mercury had fewer neutrophils but not lymphocytes, suggesting stronger associations with innate immunity. However, the odds of infection for hemoplasmas and Bartonella spp. were generally lowest in bats with high mercury, and relationships between mercury and immunity did not mediate infection patterns. Mercury also showed species- and clade-specific relationships with infection, being associated with especially low odds for hemoplasmas in Pteronotus mesoamericanus and Dermanura phaeotis. For Bartonella spp., mercury was associated with particularly low odds in the genus Pteronotus but high odds in the Stenodermatinae.

4. Synthesis and application: Lower general infection risk in bats with high mercury despite weaker innate defense suggests contaminant-driven loss of pathogen habitat (i.e., anemia) or vector mortality as possible causes. Greater attention to these potential pathways could help disentangle relationships among contaminants, immunity, and infection in anthropogenic habitats and help forecast disease risks. Our results also suggest contaminants may increase infection risk in some taxa but not others, emphasizing the importance of considering surveillance and management at different phylogenetic scales. 
Introduction

69 Wildlife are commonly exposed to many contaminants that are ubiquitous in the environment, including heavy metals, organic compounds, and pesticides (Smith et al., 2007). Contaminants can be novel stressors that have direct impacts such as mortality (Davidson, 2004) and more subtle consequences such as immunosuppression (Grasman, 2002). For example, even relatively low concentrations of mercury $(\mathrm{Hg})$, a neurotoxic heavy metal, can impair wildlife immunity

74 (Scheuhammer, Meyer, Sandheinrich, \& Murray, 2007). When immunosuppression manifests in increased susceptibility to pathogens, environmental gradients of contaminants could increase infection prevalence or intensity in wild hosts (Becker, Albery, et al., 2020). These elevated infection risks could be especially relevant in the context of environmental changes such as gold mining and agricultural land clearing, both of which are associated with bioaccumulation of contaminants like $\mathrm{Hg}$ in aquatic and terrestrial food webs (Farella, Davidson, Lucotte, \& Daigle, 2007; Palheta \& Taylor, 1995). As land conversions such as these also facilitate novel interactions among wildlife, domestic animals, and humans, impaired immunity could further increase pathogen spillover risks (Borremans, Faust, Manlove, Sokolow, \& Lloyd-Smith, 2019).

The interactions among contaminants, immunity, and infection are notoriously difficult to study in natural systems, and empirical tests of possible directional relationships remain rare (Ross, 2002). Without captive or field experiments, natural systems must demonstrate sufficient variation in contaminant exposure and infection status to permit inference, and these criteria may be hard to meet in practice. For example, recent work on urbanized bobcats demonstrated strong effects of anticoagulant exposure on immunity in ways that should increase susceptibility, but pathogens of clinical relevance were generally rare, making it difficult to draw epidemiological inferences (Serieys et al., 2018). Additionally, effects may be difficult to detect if contaminant concentrations have low variance or are below toxicity thresholds (Fisk et al., 2005). Other examples suggest contaminants may instead decrease infection risks (Prüter et al., 2018), but the

93 degree to which such patterns might be mediated by contaminant effects on immunity are

94 unclear. Field-based assessments of how variable contaminant concentrations are associated with immunity and common pathogens are necessary to disentangle directional relationships.

Here, we capitalized on high variation in $\mathrm{Hg}$ and infection across species in a diverse

97 Neotropical bat community in Belize to test associations among contaminants, immunity, and infection. $\mathrm{Hg}$ concentrations are typically highest in aquatic animals because methylmercury 
99 (MeHg), the bioaccumulative form of $\mathrm{Hg}$, is produced in aquatic ecosystems (Chumchal et al., 2011). However, such contaminants can transfer into terrestrial ecosystems when terrestrial consumers feed on aquatic prey contaminated with MeHg (Cristol et al., 2008). Neotropical bats are ecologically diverse (Gunnell \& Simmons, 2012; Rojas, Vale, Ferrero, \& Navarro, 2011), and their diet variation enables strong heterogeneity in $\mathrm{Hg}$ exposure. Specifically, our past work showed that how often species feed on aquatic prey (or prey with some life stages linked to aquatic ecosystems) determines bat fur $\mathrm{Hg}$, such that insectivores and species feeding on amphibians and fish have greater diet exposure than frugivores and sanguivores (Becker, Chumchal, et al., 2018). Such variation should produce strong associations with immunity, as even sublethal $\mathrm{Hg}$ concentrations correlate with immunity (Becker et al., 2017). Because bats can be vulnerable to extracellular pathogens and can also harbor viral and bacterial zoonoses (Brook \& Dobson, 2015), immune differences driven by dietary variation in $\mathrm{Hg}$ could have implications for disease risks to and from bats. Lastly, this region in Belize is also undergoing intensive land clearance for agriculture similar to much of Latin America (Patterson, 2016), and thus analyses of $\mathrm{Hg}$, immunity, and infection could help assess how land use affects wildlife and human health. Here we built upon our prior studies of $\mathrm{Hg}$ and of infectious disease in Neotropical bats (e.g., Becker, Chumchal, et al., 2018; Becker, Speer, et al., 2020) to address three study aims. First, we combined historic and new data on $\mathrm{Hg}$ concentrations in bat fur, an indication of longterm metal exposure (Flache et al., 2015), and compared contaminant load over a three-year period and two sites. This greater within-species sample size allowed us to more robustly assess whether bat dietary connectivity to aquatic ecosystems predicts $\mathrm{Hg}$ bioaccumulation and if such patterns persist despite spatiotemporal variation. Additionally, because agriculture can increase environmental concentrations of $\mathrm{Hg}$ (Costantini, Czirják, Bustamante, Bumrungsri, \& Voigt, 2019; Farella et al., 2007), we also tested whether more recently sampled bats within this rapidly changing landscape had higher Hg exposure. Second, using blood samples, we tested whether elevated bat $\mathrm{Hg}$ is correlated with impaired immune function. Expanding our species-specific analyses in vampire bats (Desmodus rotundus; Becker et al., 2017) across the entire bat community, we predicted that individuals with high $\mathrm{Hg}$ would have lower measures of cellular

128 Bartonella spp. Both are common in Neotropical bats (Ikeda et al., 2017), including in these 
showed infection can correlate with immunity in vampire bats specifically (Becker, Czirják, et al., 2018). However, how $\mathrm{Hg}$ shapes infection risk, and if such patterns are mediated by immunological relationships, is unknown. If $\mathrm{Hg}$ is associated with lower cellular immunity across bat species, we would expect greater concentrations to manifest in higher infection risks.

Methods

Bat sampling

137 During April 28 to May 42014 and April 24 to May 6 2017, we sampled 249 bats from 29 species captured in two areas of the Orange Walk District of Belize: Lamanai Archeological Reserve (LAR) and Ka'Kabish (KK). The LAR is bordered by the New River Lagoon, forest, and agriculture, while $\mathrm{KK}$ is a remnant forest patch surrounded by agriculture located $10 \mathrm{~km}$ away. At least 44 of the 70 bat species in Belize have been recorded in this region (Herrera, Duncan, Clare, Fenton, \& Simmons, 2018; Reid, 1997). Bats were captured with mist nets from 19:00 until 22:00, and harp traps were also set from 18:00 to 05:00.

Bats were placed in individual cloth bags until processing and were identified to species based on morphology, including but not limited to body mass and forearm length (Reid, 1997). For $\mathrm{Hg}$ analysis, we trimmed $<10 \mathrm{mg}$ of fur from the dorsal or ventral region. Scissors were cleaned with ethanol between processed bats, and samples were stored in individual cryovials or Ziploc bags. From a subset of bats sampled in 2017, we collected 3-30 $\mu \mathrm{L}$ of blood by lancing the propatagial vein with sterile needles (23-30G; size and volume were dependent on bat mass), followed by collection using heparinized capillary tubes. Thin blood smears were prepared on glass slides and stained with Wright-Geimsa (Astral Diagnostics Quick III) to characterize cellular immunity. Remaining blood was stored on Whatman FTA cards (room temperature) or RNAlater (room temperature for four weeks and then $-20^{\circ} \mathrm{C}$ ) to preserve DNA. All bats were released after processing. Sampling followed guidelines for safe and humane handling of bats issued by the American Society of Mammalogists (Sikes, Care, \& Mammalogists, 2016) and was approved by the University of Georgia Animal Care and Use Committee (A2014 04-016-Y3$\mathrm{WL} / 2 / 1 / 17(16)$, and WL/2/1/17(19). Sample size for Hg varied by year $(2014=98,2017=148)$ and site $(\mathrm{LAR}=163, \mathrm{KK}=83)$ and ranged from $1-58$ individuals per species $(\overline{\mathrm{x}}=30 \pm 29 \mathrm{SE})$. 
Fur Hg analysis

162 Bat fur was analyzed for total $\mathrm{Hg}(\mathrm{THg})$ at the Texas Christian University Aquatic Ecology Laboratory. THg data from 2014 were published previously (Becker, Chumchal, et al., 2018). Fur samples were rinsed in a 2:1 chloroform:methanol solution and dried overnight in a fume

165 hood and reported on a fresh weight basis. We quantified THg with a direct Hg analyzer (DMA80, Milestone, CT, USA) and analyzed National Research Council Canada reference material DORM 4 (certified value $=0.412 \pm 0.036 \mathrm{mg} / \mathrm{kg}$ ) every 10 samples for quality control; mean recovery was $94.32 \pm 0.96 \%$ for 2017 data. Limited fur resulted in some samples falling below detection limit (DL), which was higher in 2014 ( $\sim 0.48 \mathrm{ng})$. THg values below DL were estimated as 50\% DL, and we used the 2014 DL to standardize concentrations (Rainwater et al., 2005). Fur THg was expressed in $\mathrm{mg} / \mathrm{kg}$ and $\log _{10}$-transformed prior to statistical analyses. $\mathrm{THg}$ is a proxy for $\mathrm{MeHg}$, which comprises $71-95 \%$ of $\mathrm{Hg}$ in bat fur (Yates et al., 2013).

Statistical analysis of fur $\mathrm{THg}$

175 To first link bats to aquatic food webs (i.e., the primary source of dietary $\mathrm{Hg}$ exposure; Becker, Chumchal, et al., 2018), we used the EltonTraits database to classify bat species according to the proportion of diet consisting of potentially aquatic prey: invertebrates, ectothermic tetrapods, and fish (Wilman et al., 2014). We used phylogenetic generalized linear mixed models (GLMMs) to test how THg varied with bat diet, site (LAR and KK), and year (2014 and 2017). We fit candidate models that considered all fixed effects and their two- and three-way interactions. We fit the phylogenetic GLMM using the brms package in R, default priors, and Gaussian errors (Bürkner, 2017). We included random effects for species and phylogeny, the latter of which used a phylogenetic covariance matrix derived from the Open Tree of Life through the rotl and ape packages (Michonneau, Brown, \& Winter, 2016; Paradis, Claude, \& Strimmer, 2004). We ran four chains for 20,000 iterations with a burn-in period of 10,000, thinned every 10 steps, for a total 4,000 samples. We compared GLMMs using leave-one-out cross-validation (LOOIC) and assessed fit with a Bayesian $R^{2}$, including the total modeled variance and that attributed to only the fixed effects (Gelman, Goodrich, Gabry, \& Vehtari, 2019; Vehtari, Gelman, \& Gabry, 2017). We then estimated fixed effects per predictor (means and 95\% highest density intervals [HDI]) and visualized fitted values using 100 random draws from the GLMM posterior distribution. 


\section{Quantifying immunity and bacterial infection}

193 Using blood smears, we first estimated total white blood cell (WBC) counts as the mean number of leukocytes from 10 fields of view (400X) with a light microscope (Schneeberger, Czirják, \& Voigt, 2013). We next used differential WBC counts (1000X) to quantify the relative abundance of neutrophils and lymphocytes from 100 leukocytes. Neutrophils are components of the innate immune system, whereas lymphocytes are involved in adaptive responses like immunoglobulin production (Lanier, 2013). We derived absolute neutrophil and lymphocyte counts separately by multiplying total and differential WBCs. Elevated WBC counts can indicate a more robust cellular defense or an inflammatory response to acute infection.

To detect bacterial pathogens, we extracted genomic DNA from blood using QIAamp DNA Investigator Kits and DNeasy Blood and Tissue Kits (Qiagen). Before extracting RNAlater-preserved blood, samples were vortexed with $1 \mathrm{~mL} 1 \mathrm{X}$ phosphate-buffered saline and centrifuged for three minutes at $4000 \mathrm{RPM}$ and $12{ }^{\circ} \mathrm{C}$ to prevent bacteria from floating in RNAlater; $200 \mu \mathrm{L}$ from the bottom of the tube was then used for extraction. We used PCR to test for hemoplasmas (targeting the 16S rRNA gene) and Bartonella spp. (targeting the gltA gene) using previous diagnostic protocols (Bai, Gilbert, Fox, Osikowicz, \& Kosoy, 2016; Volokhov et al., 2017). Hemoplasma data and sequences have been published previously (Becker, Speer, et al., 2020). Efforts to characterize Bartonella spp. in this bat community are ongoing, but prior studies of Belize vampire bats indicate high glt $A$ sequence similarity to sequences from vampire bats in Mexico, Neotropical bat flies, and other Neotropical bats (Becker, Bergner, et al., 2018).

214 We first used phylogenetic GLMMs to test the overall relationship between THg and both

215 absolute neutrophil and lymphocyte counts. Each model included THg as the fixed effect, 216 alongside sex and body condition (mass/forearm length) as covariates that could also affect

217 leukocyte counts, with species and phylogeny as random effects. We used a Gaussian

218 distribution for $\log _{10}$-transformed WBC counts. We next fit phylogenetic GLMMs with binomial 219 errors to test associations between THg and infection with hemoplasmas and Bartonella spp. We 220 then used causal mediation analyses (CMA) to test support for directional relationships among $221 \mathrm{THg}$, immunity, and infection (Imai, Keele, \& Tingley, 2010). Similar to structural equation 
$223 \mathrm{THg}$ ) and a response (i.e., infection) into the direct effect and the indirect effect mediated

224 through a third variable (i.e., immunity; Fig. S1). CMA then estimates the proportion of the total

225 effect mediated through the indirect effect using a mediator model, which was each of the

226 GLMMs predicting leukocyte counts by THg, and an outcome model. Here, we fit two GLMMs

227 per pathogen that modeled infection as a function of $\mathrm{THg}$ and each WBC count. We then used

228 the brms and sjstats packages to estimate these direct and indirect effects and in turn the

229 proportion of the total relationship (THg and infection) mediated by the indirect relationship

230 between $\mathrm{THg}$ and immunity and immunity and infection .

$231 \quad$ Because bat ecology likely dictates exposure to contaminants and pathogens, we assessed

232 species-specific patterns in $\mathrm{Hg}$-infection relationships. We fit logistic regressions for each bat

233 species and pathogen when sample sizes were greater than two individuals. As these small

234 samples can bias odds ratio estimates, we used the logistf package to implement Firth's bias

235 reduction (Heinze \& Schemper, 2002). For species with no variance in infection, we assigned log

236 odds of zero. Across these species, we next estimated phylogenetic signal (Pagel's $\lambda$ ) in the log

237 odds using the caper package and used phylogenetic generalized least squares to test if log odds

238 covaried with sample size (Orme, 2013). We then used phylogenetic factorization to identify

239 clades with different log odds at various taxonomic depths. We used the taxize and phylofactor

240 packages to obtain taxonomic information for each species and partition log odds as a Gaussian

241 response in a GLM (Chamberlain \& Szöcs, 2013; Washburne et al., 2019). We included sample

242 size as a weighting variable and used Holm's sequentially rejective test to determine the number

243 of significant clades.

\section{Results}

246 Neotropical bat fur $\mathrm{THg}$

247 Expanding our initial studies of fur THg across this Neotropical bat community in 2014, we

248 found that THg varied up to five orders of magnitude across species, sites, and years (Fig. 1).

249 Our top GLMM included interactions between diet and year and between year and site (Table 1).

250 Across years, the proportion of potentially aquatic prey in diet positively predicted $\mathrm{THg}$ but more

251 so in $2014(\beta=0.019,95 \%$ HDI: 0.011-0.026) than in 2017 ( $\beta=0.016,95 \%$ HDI: 0.008-0.023;

252 Fig. 2A). We also identified strong spatiotemporal variation, such that fur $\mathrm{THg}$ increased 
between 2014 and 2017 for KK ( $\tilde{x}=0.46$ to 0.66 ) but slightly decreased for LAR ( $\tilde{x}=0.52$ to $0.49)$.

Associations with immunity and infection

Across bats sampled in 2017 with $\mathrm{Hg}$ and WBC data $(n=52)$, our GLMMs showed that higher

THg was associated with fewer neutrophils ( $\beta=0.53,95 \%$ HDI:- 0.94 to -0.17$)$ but not lymphocytes ( $\beta=0.37,95 \%$ HDI: -0.85 to 0.02 ; Fig. $2 \mathrm{~B}$ ) after adjusting for sex and condition; these two covariates had weak associations with leukocytes (Table S1). However, higher THg was also associated with lower odds of infection for hemoplasmas (OR=0.19, 95\% HDI: 0.04 0.79, $n=134)$ and Bartonella spp. (OR=0.18, 95\% HDI: 0.03-0.84, $n=117$; Fig. 3A). Accordingly, CMAs found that the relationship between $\mathrm{THg}$ and either WBC did not mediate any of the relationships between $\mathrm{THg}$ and infection for both pathogens (Table S2).

When we used logistic regression to analyze individual relationships between $\mathrm{THg}$ and infection per bat species and pathogen, we only found significant protective effects for Pteronotus mesoamericanus and hemoplasmas after adjusting for multiple comparisons $(\ln (\mathrm{OR})=-10.20, p=0.001$; Table 2$)$. We also detected a strong negative association between $\mathrm{THg}$ and Bartonella in this species $(\ln (\mathrm{OR})=3.34)$, but no $\log$ odds were significantly different from zero after adjustment. Most species instead had null relationships between $\mathrm{THg}$ and infection

271 (i.e., 36\% for hemoplasmas and 43\% for Bartonella spp.) or relatively weaker negative effects

272 (e.g., Dermanura phaeotis, $\ln (\mathrm{OR})=-7.58$ for hemoplasmas; $P$. fulvus, $\ln (\mathrm{OR})=-3.35$ for

273 Bartonella spp.). These negative $\mathrm{THg}$-infection associations were identified for $29 \%$ of species

274 for both pathogens. We also estimated similar proportions of positive $\mathrm{THg}$ associations for 275 hemoplasmas (36\%) and Bartonella spp. (29\%). Desmodus rotundus had the strongest positive $276 \mathrm{THg}$ effect size for hemoplasma infection $(\ln (\mathrm{OR})=2.40)$, whereas Dermanura watsoni had the 277 largest positive THg effect size for Bartonella spp. infection $(\ln (\mathrm{OR})=8.9)$.

278 Comparative analyses of the log odds ratios across bat species revealed no phylogenetic 279 signal for the relationship between $\mathrm{THg}$ and hemoplasmas $(\lambda=0)$ but strong phylogenetic signal 280 for the relationship between THg and Bartonella spp. $(\lambda=0.84)$. Log odds ratios were not 281 associated with sample size for hemoplasmas $\left(F_{1,12}=1.46, p=0.25\right)$ or Bartonella spp. $\left(F_{1,12}=0.25\right.$, $282 p=0.63)$. Phylogenetic factorization further identified species-specific or taxonomic patterns in 283 the magnitude and direction of effect size. For hemoplasmas, the odds of infection were 
significantly lower for Pteronotus mesoamericanus and Dermanura phaeotis when compared to the remaining sampled bat phylogeny. For Bartonella spp., however, the odds of infection were significantly lower for the genus Pteronotus (mean $\ln (\mathrm{OR})=-3.34)$ and significantly higher for the subfamily Stenodermatinae (Dermanura spp. and Sturnira parvidens, mean $\ln (\mathrm{OR})=5.79$; Fig. 3B). Post-hoc GLMs showed that bats in the Stenodermatinae had especially negative associations between THg and neutrophils $(\beta=-2.14, p=0.001)$ but not lymphocytes $(\beta=-0.43$, $p=0.63)$, although these analyses were limited by small sample size $(n=7)$.

\section{Discussion}

Interactions among contaminants, immunity, and infection are difficult to disentangle in natural systems, but quantifying their proposed causal relationships can inform how land-use change affects wildlife health and human disease risks. By capitalizing on a diverse Neotropical bat system with high variation in $\mathrm{Hg}$ bioaccumulation and bacterial pathogens, we found higher $\mathrm{THg}$ was associated with fewer neutrophils but also lower odds of infection across the host community. However, our species-specific and taxonomic analyses showed $\mathrm{THg}$ had protective effects for hemoplasmas and Bartonella spp. in the genus Pteronotus, whereas THg was associated with fewer neutrophils and elevated infection in the subfamily Stenodermatinae. These contrasting relationships suggest contaminant-driven loss of pathogen habitat (i.e., anemia) or vector mortality versus immunosuppression as possible causal mechanisms, respectively, and identify clades of bats that may be especially resilient or vulnerable to infection risks from $\mathrm{Hg}$ exposure. Such findings more generally suggest contaminants may increase infection risk in some taxa but not others, emphasizing the importance of considering surveillance and management at different phylogenetic scales (Graham, Storch, \& Machac, 2018). demonstrated that $\mathrm{Hg}$ exposure increases with potentially aquatic prey (or prey with some life

312 Positive associations with diets linked to aquatic ecosystems across sites and years provides 313 additional support for trophic transfer of $\mathrm{Hg}$ through foraging (Cristol et al., 2008; Ortega- 
likely underlies other cases of guild-specific Hg bioaccumulation in bat communities (CarrascoRueda, Loiselle, \& Frederick, 2020; Korstian, Chumchal, Bennett, \& Hale, 2018). In many of these regions, bat dietary exposure to $\mathrm{Hg}$ is driven by land-use changes such as gold mining and agriculture (Carrasco-Rueda et al., 2020; Costantini et al., 2019), whereas atmospheric deposition is often the primary source of $\mathrm{Hg}$ in regions located further from anthropogenic point sources (Chételat et al., 2018; Korstian et al., 2018). The latter is a likely source of Hg in the Belize system (Becker, Chumchal, et al., 2018). However, intensified agriculture and especially slash-and-burn practices could provide other $\mathrm{Hg}$ inputs and may explain why bat $\mathrm{THg}$ increased between 2014 and 2017 in KK, the more agricultural site, but not in the protected LAR (Farella et al., 2007; Patterson, 2016).

Across bat species, fur THg was negatively correlated with neutrophil counts, which mirrors captive results and suggests impaired innate immunity (Lalancette, Morin, Measures, \& Fournier, 2003). Previously, vampire bats sampled in Belize with high fur THg had weaker innate defense (i.e., bacterial killing ability; Becker et al., 2017). Wrinkle-lipped free-tailed bats with higher $\mathrm{Hg}$ exposure also had weaker innate immunity (i.e., bacterial killing ability, lysozyme and haptoglobin concentrations; Costantini et al., 2019). Most individual bats for which we had both $\mathrm{Hg}$ and immunity data showed $\mathrm{THg}$ below toxicity and subclinical thresholds of 5-10 mg/kg (Nam et al., 2012), which suggests innate immunity could be weakened at sublethal contaminant concentrations (Lewis, Cristol, Swaddle, Varian-Ramos, \& Zwollo, 2013). Alternatively, sublethal effects of THg could combine with other stressors (e.g., reproduction,

335 food and roost availability) to impair immunity. Additional immune measures across broader land-use gradients would help characterize functional differences in defense in relation to $\mathrm{THg}$ concentrations in anthropogenic habitats (Becker, Albery, et al., 2020; Costantini et al., 2019). with hemoplasmas and Bartonella spp. decreased with fur THg across the bat community. As in other mammals, bats challenged with bacteria produce neutrophils as part of the innate immune response (Weise, Czirják, Lindecke, Bumrungsri, \& Voigt, 2017). Elevated neutrophil counts

343 two pathogens in vampire bats (Becker, Czirják, et al., 2018). Accordingly, relationships

344 between THg and immunity did not mediate the relationships between $\mathrm{THg}$ and infection, which 
contaminant-mediated pathogen mortality; for example, lead exposure likely caused helminth mortality in avian hosts (Prüter et al., 2018). As facultative intracellular pathogens, hemoplasmas and Bartonella spp. both infect red blood cells. Hg can lower erythrocyte counts (Shaw, Dash, \& Panigrahi, 1991), which could reduce resources available to both bacteria. We did not measure anemia or $\mathrm{Hg}$ in blood; however, fur $\mathrm{THg}$ strongly correlates with blood $\mathrm{THg}$, despite the former being orders of magnitude higher than the latter (Wada, Yates, Evers, Taylor, \& Hopkins, 2010). As Bartonella spp. and possibly hemoplasmas likely depend in part on vector-borne transmission (Becker, Bergner, et al., 2018; Willi et al., 2007), ectoparasite mortality from contaminants in hosts or the environment could also explain observed infection patterns (e.g., as found for some avian ectoparasites; Eeva \& Klemola, 2013). Lastly, we did not reliably age all bats, precluding age from our analyses; however older animals typically have higher fur THg (Korstian et al., 2018). If older bats also have stronger adaptive immunity (e.g., antibody titers in Saccopteryx bilineata; Schneeberger, Courtiol, Czirják, \& Voigt, 2014), age could explain negative associations between $\mathrm{THg}$ and infection.

Our species-specific analyses suggested contaminants may have variable impacts on infection risk depending on taxon. In particular, we identified possibly protective effects of $\mathrm{THg}$ on infections primarily in the genus Pteronotus, with strong negative effects for $P$. that often eat dipterans and coleopterans (Salinas-Ramos, Herrera Montalvo, León-Regagnon, Arrizabalaga-Escudero, \& Clare, 2015). Given this clade-based signal, Pteronotus bats may be particularly resilient to disease impacts of $\mathrm{Hg}$. Such effects could be in part mediated by high host-specificity of bat flies for this genus (Ter Hofstede, Fenton, \& Whitaker, 2004), particularly if high THg increases vector mortality or if aspects of bat fly biology impact vector competence (Weiss \& Aksoy, 2011). In contrast, we also identified taxa with positive relationships between $\mathrm{THg}$ and infection. For hemoplasmas, higher THg was associated with greater risk in vampire bats. As this species frequently feeds on humans and livestock (Streicker \& Allgeier, 2016), 375 neutrophils, suggesting Hg-mediated immunosuppression. Such species may thus be especially pathogen surveillance would be particularly important in habitats contaminated by agriculture or mining. Additionally, the Stenodermatinae displayed strong positive associations between $\mathrm{THg}$ and Bartonella spp. These frugivores also showed negative correlations between THg and vulnerable to infection from $\mathrm{Hg}$ exposure and could play key roles in maintaining Bartonella 
377 spp. infection cycles between bats and ectoparasites in contaminated environments (Judson,

378 Frank, \& Hadly, 2015). From another perspective, because the Stenodermatinae and Pteronotus

379 had lower and higher fur THg, respectively, low $\mathrm{Hg}$ exposure could increase susceptibility while

380 higher concentrations instead cause anemia and facilitate protective effects against erythrocytic

381 pathogens. More generally, these results highlight the importance of considering surveillance and

382 management of $\mathrm{Hg}$ exposure (e.g., through possible land use drivers) at different phylogenetic

383 scales, such as species, genus, or subfamily.

Beyond bats and their pathogens, our study more broadly emphasizes the need to assess

potential causal relationships between contaminants and infectious diseases in natural systems. In particular, we provide a novel perspective on integrating approaches from ecotoxicology with those of disease ecology to disentangle the complex relationships among contaminants, immunity, and infection. Future work that carefully integrates data on contaminant exposure, specific diet composition, multiple immune measures, and pathogen diversity (e.g., with metagenomics; Bergner et al., 2019) across site gradients of anthropogenic intensity could help identify habitats, host clades, and infections for which disease risks are highest.

\section{Acknowledgements}

394 For assistance with field logistics and permits, we thank Mark Howells, Neil Duncan, and staff of the Lamanai Field Research Center. We also thank the many colleagues who helped net bats during 2014 and 2017 bat research in Belize as well as Susan Perkins for laboratory reagents. Lastly, we thank two anonymous reviewers for constructive feedback on this manuscript.

\section{Data accessibility}

400 Data from 2017 will be deposited in Dryad Digital Repository upon acceptance. Data from 2014

401 have been published previously (Becker, Chumchal, et al., 2018).

\section{Author contributions}

404 DJB, KAS, AMB, HGB, and NBS collected samples; JMK, DJB, KAS, DVV, AMB, CLB, HD, 405 and TPS analyzed samples; DJB analyzed the data; and HGB, RKP, TRR, MBF, NBS, and 406 MMC provided funding and logistical support. DJB wrote the manuscript with input from all 407 authors. 
409 Funding

410 DJB was funded by the ARCS Foundation and Explorer's Club. Field work by DJB and KAS

411 was supported by grants from the American Museum of Natural History Theodore Roosevelt

412 Memorial Fund. Lab work by KAS and CLB was funded by the Richard Gilder Graduate School

413 Student Research Fellowship. RKP was supported by NSF DEB-1716698, the Defense

414 Advanced Research Projects Agency PREEMPT program Cooperative Agreement

415 D18AC00031, U.S. National Institutes of General Medical Sciences IDeA Program

416 (P20GM103474 and P30GM110732), and the USDA National Institute of Food and Agriculture

417 (Hatch project 1015891). NBS was supported by the American Museum of Natural History

418 Taxonomic Mammalogy Fund. JMK and MMC were supported by a Texas Christian University

419 Research and Creative Activities Fund Award, and HGB was supported by a Natural Sciences

420 and Engineering Research Council of Canada Discovery Grant. TRR was supported by the

421 Yawkey Foundation and Clemson University. The views, opinions, and/or findings expressed are

422 those of the authors and should not be interpreted as representing the official views or policies of

423 the Department of Defense or the U.S. Government. 


\section{Tables}

425 Table 1. Competing phylogenetic GLMMs predicting log fur THg concentrations across the

426 Belize bat community $(n=249)$. Models are ranked by $\triangle$ LOOIC with LOOIC SE, Akaike weights

$427\left(w_{i}\right)$ and Bayesian $R^{2}$ estimates. All models include random effects for species and phylogeny.

428

\begin{tabular}{|c|c|c|c|c|c|c|}
\hline Fixed effects & LOOIC & SE & $\triangle \mathrm{LOOIC}$ & $w_{i}$ & $\boldsymbol{R}^{2}{ }_{m}$ & $\boldsymbol{R}^{2}{ }_{c}$ \\
\hline $\begin{array}{l}\sim \text { diet }+ \text { year }+ \text { site }+ \text { year:site }+ \\
\text { diet:year }\end{array}$ & 76.21 & 38.83 & 0.00 & 0.39 & 0.80 & 0.92 \\
\hline $\begin{array}{l}\sim \operatorname{diet}+\text { year }+ \text { site }+ \text { year:site }+ \\
\text { diet:year }+ \text { diet:site }\end{array}$ & 77.22 & 38.12 & 1.01 & 0.24 & 0.79 & 0.92 \\
\hline$\sim \operatorname{diet} *$ year $*$ site & 77.64 & 37.03 & 1.43 & 0.19 & 0.79 & 0.92 \\
\hline$\sim \operatorname{diet} *$ year + site & 78.78 & 39.63 & 2.57 & 0.11 & 0.80 & 0.92 \\
\hline $\begin{array}{l}\sim \text { diet }+ \text { year }+ \text { site }+ \text { diet:site }+ \\
\text { diet:year }\end{array}$ & 79.57 & 38.96 & 3.36 & 0.07 & 0.79 & 0.92 \\
\hline $\begin{array}{l}\sim \text { diet }+ \text { year }+ \text { site }+ \text { diet }: \text { site }+ \\
\text { year:site }\end{array}$ & 86.87 & 33.20 & 10.66 & $>0.01$ & 0.77 & 0.91 \\
\hline$\sim$ diet + year $*$ site & 89.33 & 33.93 & 13.13 & $>0.01$ & 0.78 & 0.91 \\
\hline$\sim \operatorname{diet} *$ site + year & 89.97 & 33.94 & 13.77 & $>0.01$ & 0.77 & 0.91 \\
\hline$\sim$ diet + year + site & 94.43 & 34.22 & 18.23 & $>0.01$ & 0.78 & 0.91 \\
\hline
\end{tabular}


430 Table 2. Results of species-specific logistic regressions (using Firth's bias reduction method)

431 between bat fur THg concentrations and infection status per each bacterial pathogen.

\begin{tabular}{|c|c|c|c|c|c|c|c|c|}
\hline \multirow[b]{2}{*}{ Bat species } & \multicolumn{4}{|c|}{ Hemoplasmas } & \multicolumn{4}{|c|}{ Bartonella } \\
\hline & $\ln (\mathrm{OR})$ & $p$ & $\sigma^{2}$ & $n$ & $\ln (\mathrm{OR})$ & $p$ & $\sigma^{2}$ & $n$ \\
\hline $\begin{array}{l}\text { Eptesicus } \\
\text { furinalis }\end{array}$ & -1.545 & 0.4569 & 0.214 & 8 & 0 & 1 & 0 & 7 \\
\hline $\begin{array}{l}\text { Bauerus } \\
\text { dubiaquercus }\end{array}$ & 0 & 1 & 0 & 3 & 0 & 1 & 0 & 3 \\
\hline $\begin{array}{l}\text { Dermanura } \\
\text { watsoni }\end{array}$ & -0.128 & 0.984 & 0.267 & 6 & 8.904 & 0.3177 & 0.167 & 6 \\
\hline $\begin{array}{l}\text { Dermanura } \\
\text { phaeotis }\end{array}$ & -7.578 & 0.2562 & 0.278 & 9 & 4.27 & 0.5789 & 0.214 & 8 \\
\hline $\begin{array}{l}\text { Sturnira } \\
\text { parvidens }\end{array}$ & 1.099 & 0.7923 & 0.257 & 15 & 4.198 & 0.4613 & 0.194 & 9 \\
\hline Carollia sowelli & 0.213 & 0.9427 & 0.178 & 10 & -1.987 & 0.5159 & 0.233 & 10 \\
\hline $\begin{array}{l}\text { Trachops } \\
\text { cirrhosus }\end{array}$ & 0 & 1 & 0 & 3 & 0 & 1 & 0 & 3 \\
\hline $\begin{array}{l}\text { Chrotopterus } \\
\text { auritus }\end{array}$ & 0 & 1 & 0 & 3 & 0 & 1 & 0 & 3 \\
\hline $\begin{array}{l}\text { Glossophaga } \\
\text { soricina }\end{array}$ & 0.665 & 0.8421 & 0.218 & 11 & -2.373 & 0.4911 & 0.194 & 9 \\
\hline $\begin{array}{l}\text { Desmodus } \\
\text { rotundus }\end{array}$ & 2.395 & 0.3328 & 0.208 & 22 & 0.178 & 0.933 & 0.208 & 22 \\
\hline $\begin{array}{l}\text { Pteronotus } \\
\text { mesoamericanus }\end{array}$ & -10.201 & 0.0001 & 0.227 & 22 & -3.339 & 0.0159 & 0.25 & 16 \\
\hline Pteronotus fulvus & 1.653 & 0.65 & 0.25 & 4 & -3.346 & 0.4073 & 0.25 & 4 \\
\hline $\begin{array}{l}\text { Rhynchonycteris } \\
\text { naso }\end{array}$ & 0 & 1 & 0 & 4 & 0 & 1 & 0 & 3 \\
\hline $\begin{array}{l}\text { Saccopteryx } \\
\text { bilineata }\end{array}$ & 0 & 1 & 0 & 8 & 0 & 1 & 0 & 8 \\
\hline
\end{tabular}


bioRxiv preprint doi: https://doi.org/10.1101/2020.06 12 135475; this version posted December 1, 2020. The copyright holder for this preprint (which was not certified by peer review) is the author/funder, who has granted bioRxiv a license to display the preprint in perpetuity. It is made available under aCC-BY-NC-ND 4.0 International license.

\section{$433 \quad$ Figures and legends}

\section{4}

435 Figure 1. THg concentrations in bat fur across Neotropical bat species sampled in 2014 and 2017

436 across two sites in Belize. Boxplots are colored by the proportion of potentially aquatic prey in

437 bat diets from the EltonTraits database. THg concentrations are displayed on a $\log _{10}$ scale.

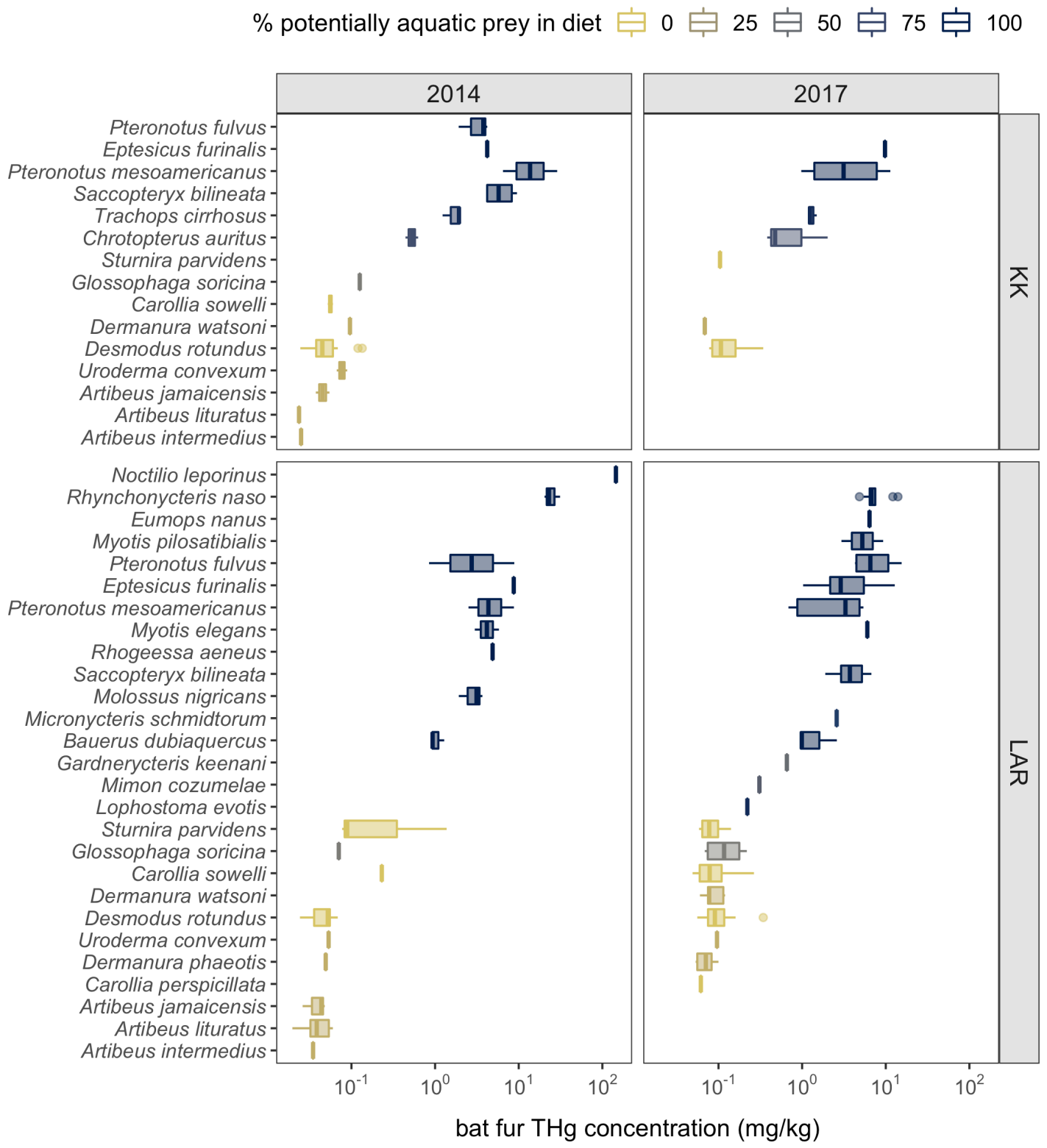


440 Figure 2. Dietary drivers of THg concentrations in Neotropical bat fur (A) and cellular immunity 441 correlates of THg (B). Points indicate individual bats and are colored by sampling year in Belize.

442 Lines display 100 random draws from the posterior distribution of the main phylogenetic

443 GLMMs. THg concentrations and absolute leukocyte counts are displayed on a $\log _{10}$ scale.

sampling year $\circ 2014$

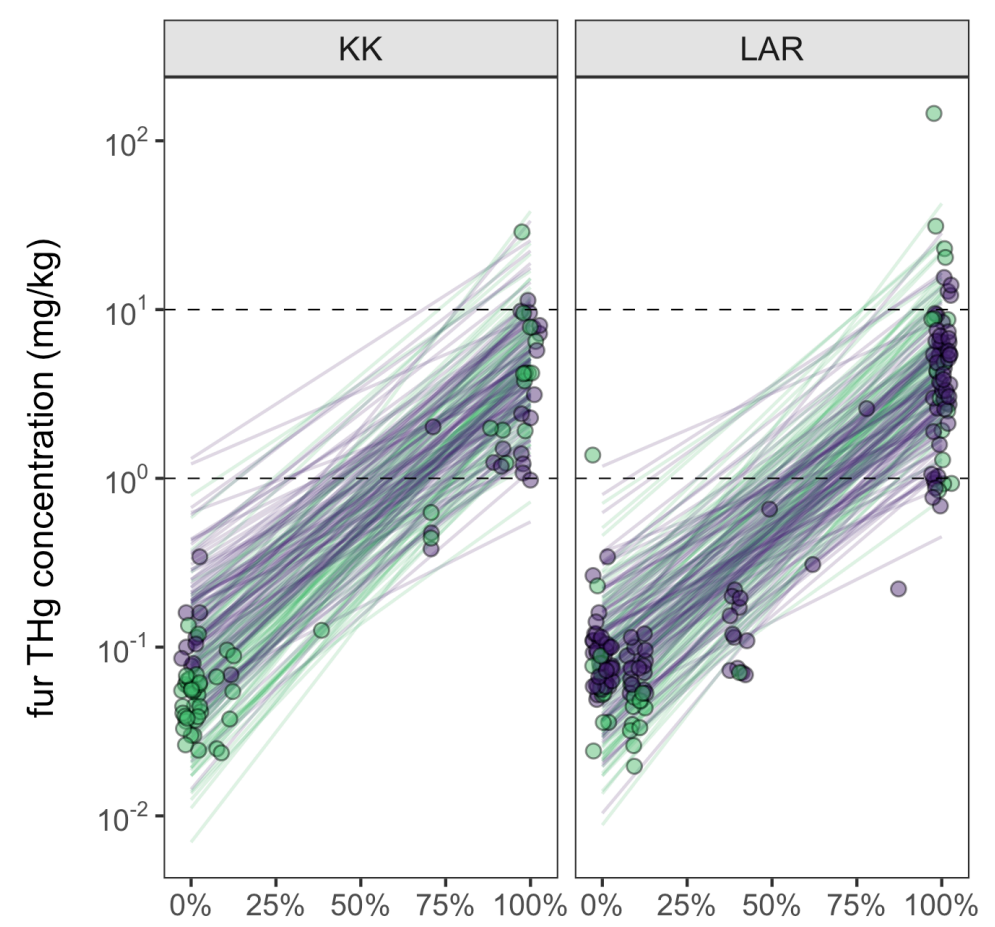

(A) potentially aquatic prey in bat diet 
447 Figure 3. Associations between fur THg and bacterial infection (A) across the Belize Neotropical

448 bat community and (B) on a per-species basis. Points in A indicate individual bats, and thin lines

449 show 100 random draws from the posterior distribution of the phylogenetic GLMMs. Points in B

450 indicate bat species, are scaled by the absolute log odds, and are colored by the direction of the

451 relationship between $\mathrm{THg}$ and infection: null effects (i.e., $\mathrm{OR}=1$, white), protective effects of

$452 \mathrm{THg}$ (i.e., OR<1, grey), and mercury as a risk factor (i.e., OR $>1$, black). Data are shown for

453 hemoplasmas (top) and Bartonella (bottom). Color indicates bat clades identified through

454 phylogenetic factorization of log odds ratios, with lines indicating clade-specific GLM fits.
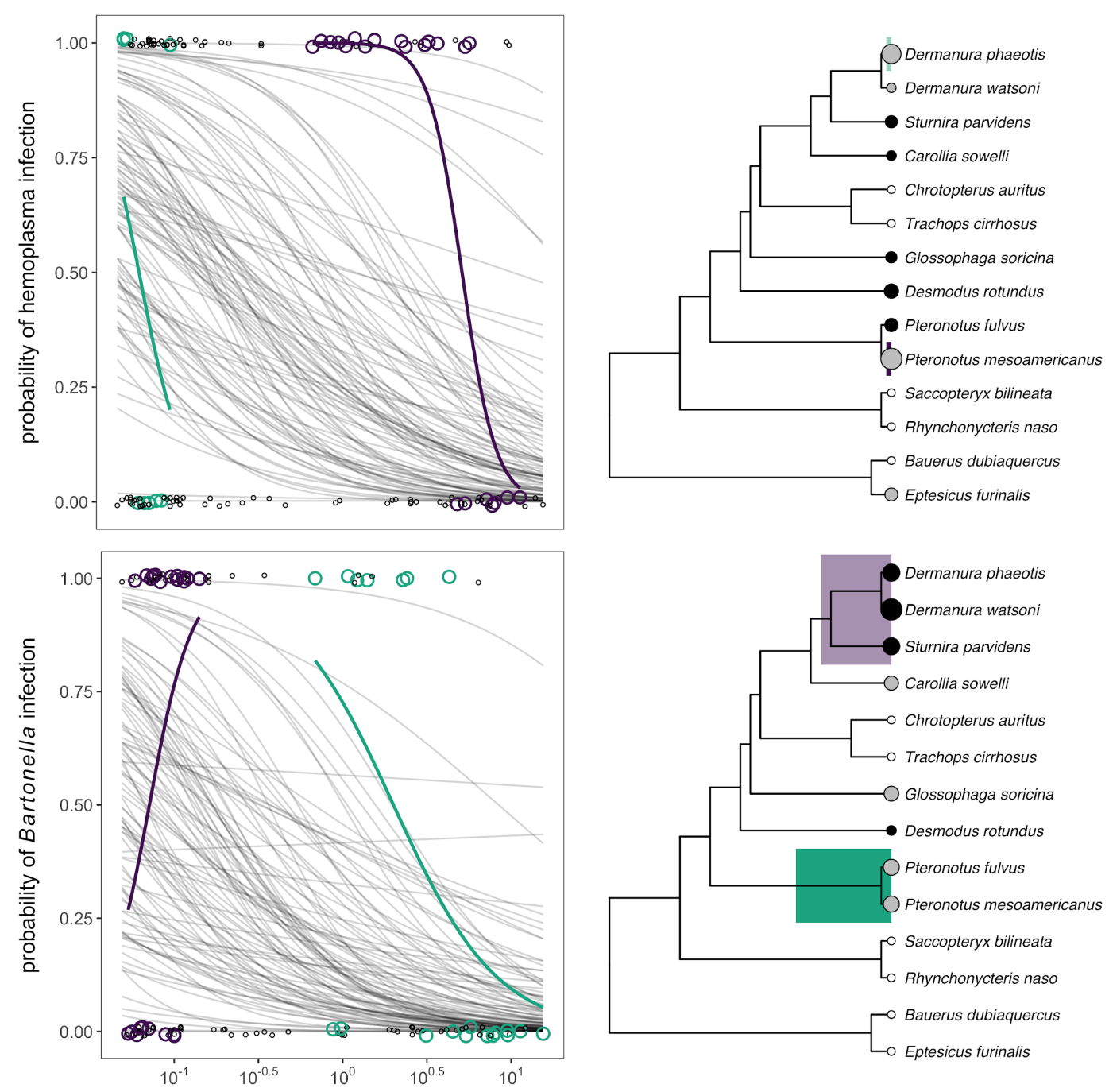


\section{References}

458 Bai, Y., Gilbert, A., Fox, K., Osikowicz, L., \& Kosoy, M. (2016). Bartonella rochalimae and b. Vinsonii subsp. Berkhoffii in wild carnivores from colorado, usa. Journal of Wildlife Diseases, 52(4), 844-849. doi: 10.7589/2016-01-015

Becker, D. J., Albery, G. F., Kessler, M. K., Lunn, T. J., Falvo, C. A., Czirják, G. Á., ... patterns in wildlife immune defence. Journal of Animal Ecology, 89(4), 972-995. doi:

Becker, D. J., Bergner, L. M., Bentz, A. B., Orton, R. J., Altizer, S., \& Streicker, D. G. (2018). spp. In vampire bats. PLOS Neglected Tropical Diseases, 12(9), e0006786. doi:

Becker, D. J., Chumchal, M. M., Bentz, A. B., Platt, S. G., Czirják, G. Á., Rainwater, T. R., ... Streicker, D. G. (2017). Predictors and immunological correlates of sublethal mercury exposure in vampire bats. Royal Society Open Science, 4(4), 170073. doi:

Becker, D. J., Chumchal, M. M., Broders, H. G., Korstian, J. M., Clare, E. L., Rainwater, T. R., ... Fenton, M. B. (2018). Mercury bioaccumulation in bats reflects dietary connectivity to aquatic food webs. Environmental Pollution, 233, 1076-1085. doi:

477 Becker, D. J., Czirják, G. Á., Volokhov, D. V., Bentz, A. B., Carrera, J. E., Camus, M. S., ... Streicker, D. G. (2018). Livestock abundance predicts vampire bat demography, immune profiles and bacterial infection risk. Phil. Trans. R. Soc. B, 373(1745), 20170089. doi: 
Becker, D. J., Speer, K. A., Brown, A. M., Fenton, M. B., Washburne, A. D., Altizer, S., ... Volokhov, D. V. (2020). Ecological and evolutionary drivers of haemoplasma infection and bacterial genotype sharing in a Neotropical bat community. Molecular Ecology, 29(8), 1534-1549. doi: 10.1111/mec.15422

Bergner, L. M., Orton, R. J., Filipe, A. da S., Shaw, A. E., Becker, D. J., Tello, C., ... Streicker, D. G. (2019). Using noninvasive metagenomics to characterize viral communities from wildlife. Molecular Ecology Resources, 19(1), 128-143. doi: 10.1111/1755-0998.12946

Brook, C. E., \& Dobson, A. P. (2015). Bats as 'special'reservoirs for emerging zoonotic pathogens. Trends in Microbiology, 23(3), 172-180.

Bürkner, P.-C. (2017). brms: An R package for Bayesian multilevel models using Stan. Journal of Statistical Software, 80(1), 1-28.

Carrasco-Rueda, F., Loiselle, B. A., \& Frederick, P. C. (2020). Mercury bioaccumulation in tropical bats from a region of active artisanal and small-scale gold mining. Ecotoxicology,

498 Chamberlain, S. A., \& Szöcs, E. (2013). taxize: Taxonomic search and retrieval in R. F1000Research, 2.

500 Chételat, J., Hickey, M. B. C., Poulain, A. J., Dastoor, A., Ryjkov, A., McAlpine, D., ... 501 Zanuttig, M. (2018). Spatial variation of mercury bioaccumulation in bats of Canada linked to atmospheric mercury deposition. Science of The Total Environment, 626, 668677. doi: 10.1016/j.scitotenv.2018.01.044 
Chumchal, M. M., Rainwater, T. R., Osborn, S. C., Roberts, A. P., Abel, M. T., Cobb, G. P., ...

505 Toxicology and Chemistry, 30(5), 1153-1162.

Costantini, D., Czirják, G. Á., Bustamante, P., Bumrungsri, S., \& Voigt, C. C. (2019). Impacts of land use on an insectivorous tropical bat: The importance of mercury, physio-

Cristol, D. A., Brasso, R. L., Condon, A. M., Fovargue, R. E., Friedman, S. L., Hallinger, K. K., ... White, A. E. (2008). The Movement of Aquatic Mercury Through Terrestrial Food Webs. Science, 320(5874), 335-335. doi: 10.1126/science.1154082

Davidson, C. (2004). Declining downwind: Amphibian population declines in California and

Eeva, T., \& Klemola, T. (2013). Variation in prevalence and intensity of two avian ectoparasites in a polluted area. Parasitology, 140(11), 1384-1393.

519 Farella, N., Davidson, R., Lucotte, M., \& Daigle, S. (2007). Nutrient and mercury variations in soils from family farms of the Tapajós region (Brazilian Amazon): Recommendations for 57-93. doi: 10.1016/j.scitotenv.2005.01.051

Flache, L., Becker, N. I., Kierdorf, U., Czarnecki, S., Düring, R.-A., \& Encarnação, J. A. (2015). 
Hair samples as monitoring units for assessing metal exposure of bats: A new tool for risk assessment. Mammalian Biology-Zeitschrift Für Säugetierkunde, 80(3), 178-181.

Gelman, A., Goodrich, B., Gabry, J., \& Vehtari, A. (2019). R-squared for Bayesian Regression Models. The American Statistician, 73(3), 307-309. doi:

Graham, C. H., Storch, D., \& Machac, A. (2018). Phylogenetic scale in ecology and evolution.

Grasman, K. A. (2002). Assessing immunological function in toxicological studies of avian wildlife. Integrative and Comparative Biology, 42(1), 34-42.

Gunnell, G. F., \& Simmons, N. B. (2012). Evolutionary history of bats: Fossils, molecules and morphology. Cambridge University Press.

Heinze, G., \& Schemper, M. (2002). A solution to the problem of separation in logistic regression. Statistics in Medicine, 21(16), 2409-2419.

540 Herrera, J. P., Duncan, N., Clare, E., Fenton, M. B., \& Simmons, N. (2018). Disassembly of Fragmented Bat Communities in Orange Walk District, Belize. Acta Chiropterologica,

543 Ikeda, P., Seki, M. C., Carrasco, A. O. T., Rudiak, L. V., Miranda, J. M. D., Gonçalves, S. M. M., ... others. (2017). Evidence and molecular characterization of Bartonella spp. And

546 Imai, K., Keele, L., \& Tingley, D. (2010). A general approach to causal mediation analysis. 
551 Korstian, J. M., Chumchal, M. M., Bennett, V. J., \& Hale, A. M. (2018). Mercury contamination in bats from the central United States. Environmental Toxicology and Chemistry, 37(1),

Lalancette, A., Morin, Y., Measures, L., \& Fournier, M. (2003). Contrasting changes of sensitivity by lymphocytes and neutrophils to mercury in developing grey seals.

557 Lanier, L. L. (2013). Shades of grey-The blurring view of innate and adaptive immunity. Nature Reviews Immunology, 13(2), 73.

Lewis, C. A., Cristol, D. A., Swaddle, J. P., Varian-Ramos, C. W., \& Zwollo, P. (2013). Archives of Environmental Contamination and Toxicology, 64(2), 327-336.

Michonneau, F., Brown, J. W., \& Winter, D. J. (2016). rotl: An R package to interact with the Open Tree of Life data. Methods in Ecology and Evolution. doi: 10.1111/2041210X.12593

565 Nam, D.-H., Yates, D., Ardapple, P., Evers, D. C., Schmerfeld, J., \& Basu, N. (2012). Elevated mercury exposure and neurochemical alterations in little brown bats (Myotis lucifugus) from a site with historical mercury contamination. Ecotoxicology, 21(4), 1094-1101. doi:

569 Orme, D. (2013). The caper package: Comparative analysis of phylogenetics and evolution in R. R Package Version, 5(2). Retrieved from $\mathrm{ftp}: / /$ ctan.mirrorcatalogs.com/cran/web/packages/caper/vignettes/caper.pdf

572 Ortega-Rodriguez, C. L., Chumchal, M. M., Drenner, R. W., Kennedy, J. H., Nowlin, W. H., 
Barst, B. D., ... Lauck, K. C. (2019). Relationship Between Methylmercury Spiders. Environmental Toxicology and Chemistry, 38(11), 2503-2508.

576 Palheta, D., \& Taylor, A. (1995). Mercury in environmental and biological samples from a gold mining area in the Amazon region of Brazil. Science of the Total Environment, 168(1), 63-69.

Paradis, E., Claude, J., \& Strimmer, K. (2004). APE: Analyses of phylogenetics and evolution in R language. Bioinformatics, 20(2), 289-290.

Patterson, C. (2016). Deforestation, agricultural intensification, and farm resilience in Northern Belize: 1980-2010 (Thesis, University of Otago). University of Otago. Retrieved from https://ourarchive.otago.ac.nz/handle/10523/6858

584 Prüter, H., Franz, M., Auls, S., Czirják, G. Á., Greben, O., Greenwood, A. D., ... Krone, O. (2018). Chronic lead intoxication decreases intestinal helminth species richness and

588 Rainwater, T. R., Reynolds, K. D., Cañas, J. E., Cobb, G. P., Andersonv, T. A., McMurry, S. T., infection intensity in mallards (Anas platyrhynchos). Science of the Total Environment,

592 Reid, F. (1997). A Field Guide to the Mammals of Central America and Southeast Mexico. OUP USA.

594 Rojas, D., Vale, Á., Ferrero, V., \& Navarro, L. (2011). When did plants become important to leaf-nosed bats? Diversification of feeding habits in the family Phyllostomidae. 
Molecular Ecology, 20(10), 2217-2228. doi: 10.1111/j.1365-294X.2011.05082.x

597

598

599

600

601

602

603

604

605

606

607

608

609

610

611

612

613

614

615

616

617

618

Ross, P. S. (2002). The role of immunotoxic environmental contaminants in facilitating the emergence of infectious diseases in marine mammals. Human and Ecological Risk Assessment: An International Journal, 8(2), 277-292.

Salinas-Ramos, V. B., Herrera Montalvo, L. G., León-Regagnon, V., Arrizabalaga-Escudero, A., \& Clare, E. L. (2015). Dietary overlap and seasonality in three species of mormoopid bats from a tropical dry forest. Molecular Ecology, 24(20), 5296-5307.

Scheuhammer, A. M., Meyer, M. W., Sandheinrich, M. B., \& Murray, M. W. (2007). Effects of environmental methylmercury on the health of wild birds, mammals, and fish. AMBIO: $A$ Journal of the Human Environment, 36(1), 12-19.

Schneeberger, K., Courtiol, A., Czirják, G. Á., \& Voigt, C. C. (2014). Immune Profile Predicts Survival and Reflects Senescence in a Small, Long-Lived Mammal, the Greater SacWinged Bat (Saccopteryx bilineata). PLoS ONE, 9(9), e108268. doi: 10.1371/journal.pone.0108268

Schneeberger, K., Czirják, G. Á., \& Voigt, C. C. (2013). Measures of the Constitutive Immune System Are Linked to Diet and Roosting Habits of Neotropical Bats. PLoS ONE, 8(1), e54023. doi: 10.1371/journal.pone.0054023

Serieys, L. E. K., Lea, A. J., Epeldegui, M., Armenta, T. C., Moriarty, J., VandeWoude, S., ... Uittenbogaart, C. H. (2018). Urbanization and anticoagulant poisons promote immune dysfunction in bobcats. Proc. R. Soc. B, 285(1871), 20172533. doi:

10.1098/rspb.2017.2533

Shaw, B. P., Dash, S., \& Panigrahi, A. K. (1991). Effect of methyl mercuric chloride treatment on haematological characteristics and erythrocyte morphology of Swiss mice. 
Environmental Pollution, 73(1), 43-52.

620 Sikes, R. S., Care, A., \& Mammalogists, U. C. of the A. S. of. (2016). 2016 Guidelines of the American Society of Mammalogists for the use of wild mammals in research and

Smith, P. N., Cobb, G. P., Godard-Codding, C., Hoff, D., McMurry, S. T., Rainwater, T. R., \& Reynolds, K. D. (2007). Contaminant exposure in terrestrial vertebrates. Environmental

Speir, S. L., Chumchal, M. M., Drenner, R. W., Cocke, W. G., Lewis, M. E., \& Whitt, H. J. a diet of emergent aquatic insects. Environmental Toxicology and Chemistry, 33(11),

Streicker, D. G., \& Allgeier, J. E. (2016). Foraging choices of vampire bats in diverse

Ter Hofstede, H. M., Fenton, M. B., \& Whitaker, J. O. (2004). Host and host-site specificity of bat flies (Diptera: Streblidae and Nycteribiidae) on Neotropical bats (Chiroptera). Canadian Journal of Zoology, 82(4), 616-626.

636 Vehtari, A., Gelman, A., \& Gabry, J. (2017). Practical Bayesian model evaluation using leaveone-out cross-validation and WAIC. Statistics and Computing, 27(5), 1413-1432.

638 Volokhov, D. V., Becker, D. J., Bergner, L. M., Camus, M. S., Orton, R. J., Chizhikov, V. E., ... Streicker, D. G. (2017). Novel hemotropic mycoplasmas are widespread and genetically diverse in vampire bats. Epidemiology \& Infection, 145(15), 3154-3167.

641 Wada, H., Yates, D. E., Evers, D. C., Taylor, R. J., \& Hopkins, W. A. (2010). Tissue mercury 
concentrations and adrenocortical responses of female big brown bats (Eptesicus fuscus)

Washburne, A. D., Silverman, J. D., Morton, J. T., Becker, D. J., Crowley, D., Mukherjee, S., ... phylogenetic scales of ecological data. Ecological Monographs, 0(0), e01353. doi:

649 Weise, P., Czirják, G. A., Lindecke, O., Bumrungsri, S., \& Voigt, C. C. (2017). Simulated bacterial infection disrupts the circadian fluctuation of immune cells in wrinkle-lipped bats (Chaerephon plicatus). PeerJ, 5, e3570. doi: 10.7717/peerj.3570

Weiss, B., \& Aksoy, S. (2011). Microbiome influences on insect host vector competence. Trends in Parasitology, 27(11), 514-522.

654 Willi, B., Boretti, F. S., Tasker, S., Meli, M. L., Wengi, N., Reusch, C. E., ... Hofmannnew insights. Veterinary Microbiology, 125(3-4), 197-209. doi: 